\title{
Foods Derived from Cloned Animals and Management Policies in Worldwide
}

\author{
Soojin Lee, Yangho Jang, Hyobi Kim, Myoungheon Lee ${ }^{1}$, Byungjae So ${ }^{1}$, \\ Byoungchul Yang ${ }^{2}$, Jongkoo Kang ${ }^{3}$, and Nonghoon Choe* \\ College of Veterinary Medicine and Department of Veterinary Public Health, Konkuk University, Seoul 143-701, Korea \\ ${ }^{1}$ Animal Plant and Fisheries Quarantine and Inspection Agency, Anyang 430-757, Korea \\ ${ }^{2}$ Animal Biotechnology Division, National Institute of Animal Science, RDA, Suwon 441-706, Korea \\ ${ }^{3}$ College of Veterinary Medicine and Research Institute of Veterinary Medicine, Chungbuk National University, \\ Chungju 361-763, Korea
}

\begin{abstract}
Cloned animals are a result of asexual reproduction of animals using somatic cell nuclear transfer. Ever since the first report of a cloned sheep 'Dolly' produced by SCNT, increasing numbers of livestock, such as bovine and swine clones, have been generated worldwide. Foods derived from cloned animals have not been produced yet. However, the food safety of cloned animals has provoked controversy. The EU Food Safety Authority and U.S. Food and Drug Administration announced that milk and meat from cloned and non-cloned animals have no difference regarding food safety. However, food derived from cloned animals is considered unsuitable for eating vaguely. Moreover, there were scant information about cloned animals in Korea. Therefore, we surveyed the number of cloned animals worldwide including Korea and summarized the reports for cloned animals and discussed predictable problems.
\end{abstract}

Key words: cloning animals, foods derived from cloning, food safety, risk assessment

\section{Introduction}

Cloned animal (clone) is a result of asexual reproduction of animals using somatic cell nuclear transfer (SCNT) (Faber et al., 2004). SCNT or cloning is a process by which animals are reproduced asexually. In the cloning of animals with SCNT, the haploid gene of an oocyte is replaced by the diploid gene of a somatic cell derived from fetal or adult tissue. Since the first report of a clone sheep 'Dolly' produced by SCNT (Wilmut et al., 1997), several other species like cattle (Forsberg et al., 2002) and swine (Polejaeva et al., 2000) have been cloned actively. Cattle, which are reported to be the animals most frequently used for SCNT, were first cloned in 1998 (Cibelli et al., 1998; Yang et al., 2005), goats in 1998 (Keefer et al., 2002), pigs in 2000 (Onishi et al., 2000), rabbits in 2001 (Chesne et al., 2002) and horses in 2003 (Galli et al., 2003). Although in some cases of com-

*Corresponding author: Nonghoon Choe, College of Veterinary Medicine and Department of Veterinary Public Health, Konkuk University, Seoul 143-701, Korea. Tel: 82-2-450-3709, Fax: 822-454-3709, E-mail: nojamaji@hanmail.net panion animals (Lee et al., 2005; Shin et al., 2002) only a limited number of animals have been generated.

In Korea, cloned animals have been produced in dog (Lee et al., 2005) and gray wolf (Kim et al., 2007) for personal purpose or species conservation. Increasing numbers of livestock as bovine, swine, sheep clones have been generated worldwide. Foods derived from cloned animals have not been actualized yet. Nevertheless, there are realistic possibilities of generation or consumption of novel food (food derived from cloned animals). In 2008, the US FDA published 'animal cloning risk assessment' (FDA, 2008). The EFSA published 'EFSA draft scientific opinion on food safety of cloned animal derived food' and Japan food safety commission published 'Risk assessment of food derived from cattle, porcine and their progeny by animal cloning' in 2009 (EFSA, 2009; Food safety commission, 2009).

Food safety of cloned animals has been provoked controversy. At this time, US FDA approved the production foods derived from cloned animal (FDA, 2008). However, foods derived from cloned animals are still treated as unsafe for eating vaguely in Korea because of lame information about clone-related. In this review, we sur- 
veyed the number of cloned animals in worldwide and summarized reports for cloned animals and discussed predictable problems.

\section{Somatic Cell Nucleus Transfer (SCNT)}

Clone is a result of animals using SCNT (Faber et al., 2004). In SCNT, the nucleus of a differentiated somatic cell (a non-germline cell) is transferred, by cell fusion or direct injection, into an oocyte that has had its nucleus removed. In practice, in livestock cloning the whole somatic cell including the nucleus is usually transferred. The reconstructed embryo is artificially activated before implantation into a surrogate dam where it continues to develop and is delivered (Codex, 2008; FDA, 2008). In successful cases, the reconstructed embryo developed as a healthy newborn clone (F0). Biologically, every step in the procedure may present its own challenges.

Examples include how to select and prepare the somatic cell to be used as the nucleus donor, how to prepare the oocyte used as the nucleus recipient, how to combine these two cells, and how to initiate embryo development after fusion. Technical improvements over time are gradually increasing the proportion of clones born and technical innovations in the handling of embryos allow better control of nucleus transfer procedures. SCNT is a relatively new technology described by many as complex, technically demanding and inefficient, that continues to be developed and improved. As such, there is no universal method although the basic steps are common to most SCNT procedures at the time that this review was written.

\section{Number of Cloned Animals in Worldwide}

There is no world-wide register of clones. Therefore the number of living clones is difficult to estimate. In this review, we collected data about the number of clones at the very first. In the EU, there are about 100 cattle clones and fewer pig clones. The estimated number in USA is about 570 cattle and 10 pig clones (EFSA, 2009). In Japan, there are 557 cattle and 335 pig clones (Food safety commission, 2009). There are also clones produced elsewhere e.g. Argentina, Australia, China, Japan and New Zealand, and the estimated total number of clones alive world-wide in 2007 is less than 4000 cattle and 1500 pigs (EFSA, 2009). 33 cloned cattle have been produced by national institute of animal science and 28 cloned pigs ( 27 miniature pigs) in Korea. The relatively small number is a reflection of technical difficulties and the regulatory sta- tus. And it can be expected that the number would increase as the efficiency is improved and if cloning is approved for commercial food purposes somewhere in the world. However, even if the number of F0 clones remains small, there is potential in the future for a number of F1 and subsequent generation animals that could be produced from F0 clones and enter the food chain. Similarly, the number of clones reported as reared and living for a considerable time is limited. Only a few reports on cattle clones to date refer to animals of 6-7 years of age (Chavatte-Palmer et al., 2004; Heyman et al., 2004; Panarace et al., 2007) and no data on the full natural life span of livestock clones are available yet.

\section{Risk Assessment of Cloned Animals}

\section{Epigenetic reprogramming}

Successful SCNT requires that the nuclear activities of the differentiated somatic cell used in cloning are reset to those of an undifferentiated embryonic cell and that the new embryo is able to complete fetal development (FAO, 2002). The somatic cell nucleus has to change its gene expression pattern in relation to changes in its microenvironment in order to be able to replicate steps of normal development. This process, which is by essence epigenetic, leaves the primary DNA sequence unchanged and is reversible. Epigenetic modifications include biochemically mediated conformational changes of the proteins surrounding the DNA (i.e. chromatin) and also biochemical modifications of the DNA, particularly methylation.

Modifications of chromatin proteins are a reversible and dynamic process. In contrast DNA methylation can be much more stable. Somatic cell reprogramming consists to a large extent of DNA demethylation followed by a specific re-methylation of those DNA regions which must remain silent in a given cell type. Epigenetic mechanisms affect the expression of some genes and such modifications may be transmitted to daughter cells (Jablonka and Lamb, 2003).

The low success rates of SCNT and the underlying physiological abnormalities, frequently observed in clones during embryonic and fetal development and also soon after their birth, appear to be caused mainly by epigenetic dysregulation occuring during inappropriate reprogramming of the genome.

\section{Animal health}

SCNT results in an increased frequency of health risks to animals involved in the cloning process, but these do 
not differ qualitatively from those observed in other ARTs or natural breeding. At this time, the overall efficiency of SCNT is low (Heyman et al., 2004). Cattle and sheep exhibit a set of clinical signs collectively referred to as Large offspring syndrome (LOS) that do not appear to be present in swine or goats (FDA, 2008; Keefer et al., 2001). Surrogate dams are at risk of complications from birth if the fetus suffers from LOS, or from accumulation of fluid in the cavities of the placenta (hydrops).

Risks to clones associated with LOS include increased incidence of fetal and neonatal death and abnormalities that may require additional supportive care during the perinatal period.

Clones affected by LOS can recover and mature into normal, healthy animals. The risk of morbidity and mortality appears to decrease with age, and after approximately six months of age most bovine clones are normal and healthy as determined by physiological measurements, behavior, and veterinary examinations. Progeny of animal clones also have been reported as normal and healthy (Heyman et al., 2004; Mir et al., 2005; Norman et al., 2004b).

\section{Food consumption risk}

The composition of milk and meat from cows is influenced by the nature of the animal feed and environment (Mir et al., 2005; Palmquist et al., 1993). If subtle changes have occurred that would alter the presence of important nutrients, the most likely dietary risk for humans would be the absence of, or significant decrease in levels of vitamins and minerals whose daily requirements are in large part met by milk or meat. Therefore, nutrients for which milk or meat make a large contribution to the total daily dietary intake in humans should be considered. Compositional data of meat and milk based on reference databases obtained from sexually-reproduced animals are available for comparison with that of clones and their progeny (Caballero, 2003; Jensen et al., 1995). Several relevant studies with respect to human nutrition have been conducted on the composition of bovine milk and meat from cattle and pigs derived from clones (F0) or their progeny (F1). These analyses included carcass characteristics, water, fat, proteins and carbohydrate content, amounts and distribution of amino acids, fatty acids, vitamins and minerals, and in the case of milk, volume per lactation (Diles, 1996; Heyman et al., 2007; Norman et al., 2004; Norman and Walsh, 2004; Shibata et al., 2006; Takahashi and Ito, 2004; Tian et al., 2005; Tome et al., 2004; Walsh et al., 2003; Walker et al., 2007; Yang et al., 2007). In an exten- sive study, more than 150 parameters in 37 cow clones (F0) from 3 independent cloning experiments and 38 control animals were examined over a 3 -year period and consisted of more than 10,000 individual measurements (Heyman et al., 2007a). In this study some slight changes were observed in all 3 groups of clones, compared with their controls, e.g. in fatty acid composition of milk and muscle of bovine clones (F0) and a slight increase of stearoyl-CoA desaturase in milk and muscle. However, these variations were still within the normal range. The ViaGen data included meat composition data for five pig clones and 15 comparator animals and no biologically relevant differences were observed in fatty acid, amino acid, cholesterol, mineral and vitamin values (FDA, 2008). In a study of the composition of pig clone offspring, 242 offspring (F1) from one boar clone and 162 control pigs from the same breed were compared (Walker et al., 2007). In this study 58 parameters consisting of more than 24,000 individual measurements were examined. Only 3 individual values of the offspring were different from the normal range of the controls and 2 out of the 3 were within the normal range found in pigs, according to the USDA database (FDA, 2008). In summary, none of the studies has identified any differences outside the normal variability in the composition of meat (cattle and swine) and milk (cattle) between clones or clone progeny, and their comparators. In addition no novel constituents have been detected in products from clones or their progeny.

A 14 wk subchronic oral feeding study was conducted in rats to determine the effects of a diet containing meat and milk derived from embryonic and somatic clones. Rats were not affected by the consumption of meat and milk from bovine clones (Yamaguchi et al., 2007). Similar results were obtained by in a $21 \mathrm{~d}$ feeding test with a diet containing milk and meat from cattle clones (F0) (Heyman et al., 2007). A 12 mon oral toxicity study in the rat with meat and milk from the progeny of cattle clones (F1) was done in Japan and as the results, there were no biologically significant differences in composition among clones, their progeny and conventionally bred cattle (Yamaguchi et al., 2008).

Very few genotoxicity studies were conducted. Cloned cattle meat extracts were tested to five strains of bacteria including Salmonella Typhimurium, Escherichia coli for bacterial mutation and to Chinese hamster lung cells for chromosome aberration. As in vivo for genotoxic effects, bone marrow micronucleus test was performed in Institute of Cancer Research (ICR) mice fed with $5 \%$ and 
$10 \%$ cloned cattle meat, respectively. The results suggested that the cloned cattle meat do not induce any harmful genotoxic effects in vitro and in vivo (Lee et al., 2011). Same results also came out in the mouse micronucleus assay (Takahashi and Ito, 2004). The allergenic potential of several in vitro digested samples of meat and milk from cattle clones (F0) was assessed by intraperitoneal injection into mice following a classical immunization protocol. No statistically significant difference in the allergenic potential was observed between samples from clones and comparator control cattle (Takahashi and Ito, 2004). Also Heyman et al. did not detect differences in the allergenicity of milk and meat obtained from clones, in the rat compared with the same food products derived from noncloned animals, age and sex-matched, maintained under the same conditions (Heyman et al., 2007).

Several studies about effects on reproductive physiology were conducted. The male and female rats were fed with $5 \%$ and $10 \%$ cloned cattle meat and then analyzed reproductive parameters: sperm deformity, testosterone concentration in male rats and neonatal examination from gestation in female rats. There are no negative effects on reproductive physiology in rats fed with cloned-cattle meat (Hwang et al., 2010) Similar results were obtained in non-rodent animal, rabbit (Lee et al., 2010). There was a study on the behavioral and reproductive effect of Sprague-Dawley F1 rats fed in cloned-cattle meat. Based on behavioral and reproductive toxicity studies, there are no obvious negative effects on cloned-cattle meat as food (Yang et al., 2011).

\section{Policies to the foods derived from cloned animals in worldwide}

In US, in the risk assessment report, extensive evaluation of the available data has not identified any subtle hazards that might indicate food consumption risks in healthy clones of cattle, swine, or goats. They claimed edible products from healthy clones for meat and milk have no increased food consumption risks relative to comparable products from sexually-derived animals. And edible products derived from the progeny of clones have no additional food consumption risk(s) relative to corresponding products from other animals based on published studies (FDA 2008). Therefore, they did no need to special regulations or label.

In EU and Japan, they said that SCNT is a relatively new technology and the available data for risk assessment are limited (EFSA, 2009; Food Safety Commission, 2009). Uncertainties in the assessment arise from the small sam- ple sizes investigated in most studies and the biological variability underlying the SCNT process. However, they agreed in principle with US risk assessment that SCNT could be successfully used as a reproductive technique in cattle and pigs for healthy clones and their offspring, and healthy clones and their progeny did not show any significant differences from their conventional counterparts. Researchers are continuing about cloned animals and they will monitor international developments.

In Canada, 'Health Canada' has begun drafting the guidelines for the safety assessment of novel foods and to consider foods derived from cloned animals as novel food in 2003 (Health Canada, 2003). As novel food regulations, the producers of cloned animals must not release any cloned animals and their progeny, or foods derived from them into the human food chain unless they have been subjected to the premarket safety assessment. 'Health Canada' have not been published the safety assessment of cloned animals and product from them until now. Thus, we could not assume the number of clones or management plans associated cloned animals and foods from them.

In New Zealand, the cloning of livestock is still the experimental stage and is restricted to very small number of breeding (FSANZ, 2003). All cloned animals are confined to the research environment or in rare, New Zealand Food Safety Authority (NZFSA) indicated that there is no accepted scientific evidence that foods from cloned animals is less safe than food from noncloned animals and there is no need for specific regulation on foods derived from cloned animals.

In Korea, the ministry for food, agriculture, forestry and fisheries has been published 'Management point of cloned cattle and their products' in 2001 to national institute of animal science (NIAS). It contained that management of cloned cattle and release of shipment information. The cloned cattle is restricted in research by NIAS and cloned pig is used as transgenic technology, do not allow for meat and milk. And NIAS have been slaughtered and incinerated cloned animals in their own separate slaughterhouse only they died. There is no foods derived from cloned animals for now and there is no possibility to enter the food chain in Korea.

\section{Conclusions}

Unhealthy clones are presumed to be removed at clinical inspections and quality controls and therefore should not enter the food chain. Also unhealthy conventionally 
bred animals are excluded. Food products obtained from healthy cattle and pig clones and their progeny are within the normal range with respect to the composition of similar products obtained from conventionally-bred animals. Based on current knowledge there is no expectation that clones or their progeny would introduce any new food safety risks compared with conventionally bred animals (FAO, 2000; FAO, 2002). All food animals must satisfy regulatory requirements in order to be lawfully marketed. Any animal including clones would be detected during routine inspections and quality controls. It is assumed that such inspections and quality controls would exclude from the food chain animals with signs of disease, lesions or abnormalities, regardless of whether they are clones or noncloned animals.

Furthermore, the beef traceability system, which provides consumers of beef information such as identity number, origin and grade have been enforced in Korea. The system originated in Europe and Japan following the breakout of Bovine Spongiform Encephalophathy. With the identity number, consumers can trace back on information of beef, including breeder, date of birth, grade, place of butchery, etc. However, traceability system has been limited to cattle in Korea. In U.S, the producers have been raised livestock by herd management not like identity management and results of risk assessment indicated that there is no significant differences between clone and noncloned animal, so the producers should not need to be special labeling (FDA, 2008; Yang et al., 2007). Therefore, the consumers cannot know about detail information of pork and imported meat such as origin. The results of recent survey of public opinion on cloned animal and foods derived from them in EU indicated that cloning did not well understand by the public (European commission, 2008). A majority of EU citizens said that it was unlikely that they would buy meat or milk from cloned animals, even if a trusted source stated that such products were safe to eat. The public wanted to know about accurate information of foods whether derived from clone or nonclone animals and most of them considered labeling important. If food products from cloned animals became available, they wanted that these products should be clearly labeled. Therefore, the producers need to be containing product information for the right to know in label.

There was one thing never mentioned in risk assessment. It was semen of cloned animals. Semen from clones is already available on the market in the USA (EFSA, 2008). The studies of semen from clones were focused on viability and productivity. The results of studies indicated that progeny by artificial insemination using semen from clones was no significant differences between clone and nonclone animals. Semen from clones is available but restricted by National Institute of Animal Science (NIAS) and it can only use on researching purposes in Korea. The procedures for the collection of oocytes from animals have been proposed by the International Embryo Transfer Society as licensing guidelines and have been adopted by the world Organization for Animal Health in EU (EFSA, 2009; FDA, 2006). The International Embryo Transfer Society (IETS) recommended producers to record the information of semen such as origin like maternal source and paternal source. Small amounts of semen could breed many progenies. If semen management is insufficient, that will have a great ripple effect before people knows. Thus, the person concerned with semen requires that further management.

In Korea, it has been not allowed cloned animals to foods but major meat exporting countries such as US, Canada and EU etc., have taken indulgent treatment of clone derived foods. Moreover, there are no scientific methods to distinguish cloned animal from noncloned animal without traceability system from producers. Thus, we are also preparing for importing foods from cloned animals. The government prepares grounds to support legal sanction after adopting a policy on cloned animals.

The results of risk assessment reports for cloned animals and their progeny in US and EU indicated that there were no significant differences in physiological performance, immunological performance, compositional analysis and feeding tests. However, only limited data are available on risk assessment of cloned animal and most studies investigated in small sample sizes. These leave uncertainties in the assessment for cloned animals. Therefore, we should continuous analyze to update the data of foods from cloned animals for transient open to debate for consumers and information should be shared the public for risk communication.

\section{Acknowledgments}

This study was supported by the Korea Food \& Drug Administration Research Funds, 08082KFDA123.

\section{References}

1. Caballero, B. (2003) Encyclopedia of Food Sciences and Nutrition. Editor. Elsevier Science Ltd., pp. 3957-3963.

2. Chavatte-Palmer, P., Remy, D., Cordonnier, N., Richard, C., 
Issenman, H., Laigre, P., Heyman, Y., and Mialot, J. P. (2004) Health status of cloned cattle at different ages. Cloning Stem Cells 6, 94-100.

3. Cibelli, J. B., Stice, S. L., Golueke, P. J., Kane, J. J., Jerry, J., Blackwell, C., Ponce de Leon, F. A., and Robl, J. M. (1998) Cloned transgenic calves produced from nonquiescent fetal fibroblasts. Science 280, 1256-1258.

4. Chesne, P., Adenot, P. G., Viglietta, C., Baratte, M., Boulanger, L., and Renard, J. P. (2002) Cloned rabbits produced by nuclear transfer from adult somatic cells. Nat. Biotechnol, 20, 366-369.

5. Codex (2009) Guideline for the conduct of food safety assessment of foods derived from recombinant-DNA animals CAC/GL 68-2008. Available from:http://www.codexalimentarius.net/download/standards/10007/CXG_044e.pdf. Accessed May. 2009.

6. Diles, J. J. B., Green, R. D., Shepherd, H. H.,Mathiews, G. L., Hughes, L. J., and Miller. M. F. (1996) Relationships between body measurements obtained on yearling Brangus bulls and measures of carcass merit obtained from their steer clonemates. PAS 12, 244-249.

7. European Food Safety Authority (EFSA) (2009) Animal Health and Welfare and Environmental Impact of Animals1 derived from Cloning by Somatic Cell Nucleus Transfer (SCNT) and their Offspring and Products Obtained from those Animals, DRAFT Scientific Opinion of the Scientific Committee: Available from: http://www.efsa.europa.eu/EFSA/ efsa_locale-1178620753812_1211902019540.htm. Accessed Oct. 2009.

8. European commission (2008) Europeans' attitudes towards animal cloning : Analytical Report. Available from : http://ec. europa.eu/food/food/resources/docs/eurobarometer cloming en.pdf. Acessed Feb. 2009.

9. Faber, D. C, Ferre, L. B., Metzger, J., Robl, J. M., and Kasinathan, P. (2004) Agro-economic impact of cattle cloning. Cloning Stem Cells 6, 198-207.

10. Food and Agriculture Organization (FAO) (2000) Safety aspects of genetically modified foods of plant origin. Report of a joint $\mathrm{FAO} / \mathrm{WHO}$ expert consultation on foods derived from biotechnology. FAO/WHO, 2000. Available from:http:/ /ftp.fao.org/es/esn/ffod/gmreport.pdf. Accessed Dec. 2008.

11. Food and Agriculture Organization (FAO) (2002) Report of the third session of the codex ad hoc intergovernmental task force on foods derived from biotechnology (ALINORM 01/ 34) FAO/WHO, 2002. Available from:ftp://ftp.fao.org/codex/ alinorm03/A103 34e.pdf. Accessed Dec. 2008.

12. Food and Drug Administration (FDA) (2006) Guideline No. 179: Guidance for industry use of animal clones and clone progeny for human food and animal feed. Available from http: //www.fda.gov/cvm/Guidance/Finalguideline179.htm. Accessed Feb. 2009.

13. Food and Drug Administration (FDA) (2008a) Animal cloning risk assessment for clones and their progeny, Available from: http://www.fda.gov/cvm/cloningRA_RiskMngt.htm. Accessed Feb. 2009a.

14. Food Safety Commission (2009) Risk assessment of food derived from cattle, porcine and their progeny by animal cloning. Novel food investment working group (Japanese).

15. Food Standard Australia New Zealand (FSANZ) (2003) Review on the current status of the extent and use of cloning in animal production in Australia and New Zealand. Available from: http://www.foodstandards.gov.au/_srcfiles/Cloning Review_Final_June\%202003.pdf. Assessed Oct. 2009.

16. Galli, C., Lagutina, I., Crotti, G., Colleoni, S., Turini, P., Ponderato, N., Duchi, R., and Lazzari, G. (2003) Pregnancy: a cloned horse born to its dam twin. Nature 424, 635.

17. Health Canada (2003) Food Directorate Interim Policy on Foods from Cloned Animals. Available from: http://www.hcsc.gc.ca/fn-an/alt_formats/hpfb-dgpsa/pdf/legislation/pol-cloned _animal-clones_animaux-eng.pdf. Accessed Sep. 2009.

18. Heyman, Y., Richard, C., Rodriguez-Martinez, H., Lazzari, G., Chavatte-Palmer, P., Vignon, X., and Galli, C. (2004) Zootechnical performance of cloned cattle and offspring: preliminary results. Cloning Stem Cells. 6, 111-120.

19. Heyman, Y., Chavatte-Palmer, P., Berthelot, V., Fromentin, G., Hocquette, J. F., Martignat, L., and Renard, J. P. (2007) Assessing the quality of products from cloned cattle: an integrative approach. Theriogenology 67, 134-141.

20. Hwang, S., Lee, N. J., Hwang, J. S., Yang, B. C., Im, G. S., Ko, Y. G., Park, E. W., Park, S. B., Kang, J. K., and Seong, H. H. (2010) Effects of cloned-cattle meat on reproductive physiology in rats. Animal 4, 218-223.

21. Jablonka, E. and Lamb, M. J. (2003) The changing concept of epigenetics. Ann. N Y Acad. Sci. 981, 82-96 (2003)

22. Jensen, R. G., Couch, S. C., Bitman, J., Carlson, S. E., Hamosh, M., Newburg, D. S., and Robert, G. J. (1995) Handbook of Milk Composition. Editor. Academic Press, San Diego, p. 1574.

23. Keefer, C. L., Baldassarre, H., Keyston, R., Wang, B., Bhatia, B., Bilodeau, A. S., Zhou, J. F., Leduc, M., Downey, B. R., Lazaris, A., and Karatzas, C. N. (2001) Generation of dwarf goat (Capra hircus) clones following nuclear transfer with transfected and nontransfected fetal fibroblasts and in vitromatured oocytes. Biol. Reprod. 64, 849-856.

24. Kim, M. K., Jang, G., Oh, H. J., Yuda, F., Kim, H. J., Hwang, W. S., Hossein, M. S., Kim, J. J., Shin, N. S., Kang, S. K., and Lee, B. C. (2007) Endangered wolves cloned from adult somatic cells. Cloning Stem Cells 9, 130-137.

25. Lee, B. C., Kim, M. K., Jang, G., Oh, H. J., Yuda, F., Kim, H. J., Hossein, M. S., Kim, J. J., Kang, S. K., Schatten, G., and Hwang, W. S. (2005) Dogs cloned from adult somatic cells. Nature 436, 641.

26. Lee, N. J., Yang, B. C., Hwang, J. S., Im, G. S., Ko, Y. G., Park, E. W., Seong, H. H., Park, S. B., Kang, J. K., and Hwang, S. S. (2010) Effects of cloned-cattle meat diet on reproductive parameters in pregnant rabbits. Food Chem. Toxicol. 48, 871-876.

27. Lee, N. J., Yang, B. C., Jung, Y. R., Lee, J. W., Im, G. S., Seong, H. H., Park, J. K., Kang, J. K., and Hwang, S. S. (2011) In vitro and in vivo genotoxic effects of somatic cell nuclear transfer cloned cattle meat. Food Chem. Toxicol. 49, 2273-2278.

28. Mir, B., Zaunbrecher, G., Archer, G. S., Friend, T. H., and Piedrahita, J. A. (2005) Progeny of somatic cell nuclear trans- 
fer (SCNT) pig clones are phenotypically similar to noncloned pigs. Cloning Stem Cells. 7, 119-125.

29. Norman, H. D. and Walsh, M. K. (2004) Performance of dairy cattle clones and evaluation of their milk composition. Cloning Stem Cells. 6, 157-164.

30. Norman, H. D., Lawlor, T. J., Wright, J. R., and Powell, R. L. (2004) Performance of Holstein clones in the United States. J. Dairy Sci. 87, 729-738.

31. Onishi, A., Iwamoto, M., Akita, T., Mikawa, S., Takeda, K., Awata, T., Hanada, H., and Perry, A. C. (2000) Pig cloning by microinjection of fetal fibroblast nuclei. Science 289, 11881190.

32. Palmquist, D. L., Beaulieu, A. D., and Barbano, D. M. (1993) Feed and animal factors influencing milk fat composition. $J$. Dairy Sci. 76, 1753-1771.

33. Panarace, M., Aguero, J. I., Garrote, M., Jauregui, G., Segovia, A., Cane, L., Gutierrez, J., Marfil, M., Rigali, F., Pugliese, M., Young, S., Lagioia, J., Garnil, C., Forte Pontes, J. E., Ereno Junio, J. C., Mower, S., and Medina, M. (2007) How healthy are clones and their progeny: 5 years of field experience. Theriogenology. 67, 142-151.

34. Polejaeva, I. A., Chen, S. H., Vaught, T. D., Page, R. L., Mullins, J., Ball, S., Dai, Y., Boone, J., Walker, S., Ayares, D. L., Colman, A., and Campbell, K. H. (2000) Cloned pigs produced by nuclear transfer from adult somatic cells. Nature 407, 86-90.

35. Shibata, M., Otake, M., Tsuchiya, S., Chikyu, M., Horiuchi, A., and Kawarasaki, T. (2006) Reproductive and growth performance in Jin Hua pigs cloned from somatic cell nuclei and the meat quality of their offspring. J. Reprod. Dev. 52, 583590.

36. Shin, T., Kraemer, D., Pryor, J., Liu, L., Rugila, J., Howe, L., Buck, S., Murphy, K., Lyons, L. and Westhusin, M. (2002) A cat cloned by nuclear transplantation. Nature 415, 859.

37. Takahashi, S. and Ito, Y. (2004) Evaluation of meat products from cloned cattle: biological and biochemical properties. Cloning Stem Cells. 6, 165-171.

38. Tian, X. C., Kubota, C., Sakashita, K., Izaike, Y., Okano, R., Tabara, N., Curchoe, C., Jacob, L., Zhang, Y., Smith, S., Bormann, C., Xu, J., Sato, M., Andrew, S., and Yang, X. (2005) Meat and milk compositions of bovine clones. Proc. Natl.
Acad. Sci. USA 102, 6261-6266.

39. Tome, D., Dubarry, M., and Fromentin, G. (2004) Nutritional value of milk and meat products derived from cloning. Cloning Stem Cells 6, 172-177.

40. Walsh, M. K., Lucey, J. A., Govindasamy-Lucey, S., Pace, M. M., and Bishop, M. D. (2003) Comparison of milk produced by cows cloned by nuclear transfer with milk from noncloned cows. Cloning Stem Cells. 5, 213-219.

41. Walker, S., Christenson, R., Ruiz, R., Reeves, D., Pratt, S., Arenivas, F., Williams, N., Bruner, B., and Polejaeva, I. (2007) Comparison of meat composition from offspring of cloned and conventionally produced boars. Theriogenology. 67, 178184.

42. Wilmut, I., Schnieke, A. E., McWhir, J., Kind, A. J., and Campbell, K. H. (1997) Viable offspring derived from fetal and adult mammalian cells. Nature 385, 810-813.

43. Yamaguchi, M., Ito, Y., and Takahashi, S. (2007) Fourteenweek feeding test of meat and milk derived from cloned cattle in the rat. Theriogenology, 67, 152-165.

44. Yamaguchi, M., Ito, Itoh M., Ito, Y., and Watanabe, S. (2008) A 12 month feeding study of reproduction/development in rats fed meat/milk powder supplemented diets derived from the progeny of cloned cattle produced by somatic cell nuclear transfer. J. Reprod. Dev. 54, 321-334.

45. Yang, B. C., Lee, N. J., Im, G. S., Seoung, H. H., Park, J. K., Kang, J. K., and Hwang, S. S. (2011) A diet of somatic cell nuclear transfer cloned-cattle meat produced no toxic effects on behavioral or reproductive characteristics of $\mathrm{F} 1$ rats derived from dams fed on cloned-cattle meat. Birth Defects Res. Part B. 92, 224-230.

46. Yang, L., Chavatte-Palmer, P., Kubota, C., O'neill, M., Hoagland, T., Renard, J.P., Taneja, M., Yang, X., and Tian, X. C. (2005) Expression of imprinted genes is aberrant in deceased newborn cloned calves and relatively normal in surviving adult clones. Mol. Reprod. Dev. 71, 431-438.

47. Yang, X., Tian, X. C., Kubota, C., Page, R., Xu, J., Cibelli, J., and Seidel, G., Jr. (2007) Risk assessment of meat and milk from cloned animals. Nat. Biotechnol. 25, 77-83.

(Received 2011.12.1/Accepted 2012.6.12) 